\title{
Effect of Chemical Irrigants on the Bond Strength of a Universal Adhesive System to Dentin-Enamel Junction and Different Dentin Regions
} \author{
DDS, PhD. ${ }^{4}$ and Arife KAPTAN, DDS, PhD. ${ }^{5^{*}}$ \\ ${ }^{1}$ Department of Restorative Dentistry, Faculty of Dentistry, Cumhuriyet University, Turkey \\ ${ }^{2}$ Department of Restorative Dentistry, Faculty of Dentistry, Firat University, Turkey \\ ${ }^{3}$ Department of Restorative Dentistry, Faculty of Dentistry, Lokman Hekim University, Turkey \\ ${ }^{4}$ Department of Endodontics, Faculty of Dentistry, Hacettepe University, Turkey \\ ${ }^{5}$ Department of Pediatric Dentistry, Faculty of Dentistry, Cumhuriyet University, Turkey
}

Alper KAPTAN, DDS, PhD. ${ }^{1}$, Vahti Kılıç, DDS, PhD. ${ }^{2}$, Feridun HÜRMÜZLÜ, DDS, PhD. ${ }^{3}$, Ahmet Serper,

*Corresponding author: Dr. Arife KAPTAN, Department of Pediatric Dentistry, Faculty of Dentistry, Cumhuriyet University, Sivas, Turkey, Tel: 00-90-346-2191010/2700, Fax: 00-90-346-2191237

\begin{abstract}
Objective: The purpose of this in vitro study was to evaluate the influence of different irrigation solutions on the microshear bond strength of a universal adhesive system applied in etch \& rinse mode and self-etch mode to dentin-enamel junction (DEJ), coronal dentin, pulp chamber dentin, and floor of the pulp.

Materials and methods: The specimens were randomly divided into 4 main groups according to the irrigation solutions used: Group 1-distilled water (control), Group 2- $\mathrm{NaOCl}$ [Sodium hypochlorite], Group 3-NaOCl combined with $17 \%$ EDTA [Ethylenediaminetetraacetic acid] and Group 4-chlorhexidin gluconate. Additionally, each main group was divided into the 2 subgroups $(n=15)$ according to the application mode of the Single Bond Universal Adhesive system. After applying the adhesive to the dentin, a vinyl tube was placed on the dentin-enamel junction and dentin surfaces, then Filtek Bulk Fill Posterior composite was packed into the cylinder's lumen and was light cured. The specimens were stored in water at $37^{\circ} \mathrm{C}$ for $24 \mathrm{~h}$. A universal testing machine was used for the microshear test. The data in MPa units were subjected to two-way analysis of variance (ANOVA) and Tukey's test $(\alpha=0.05)$. Scanning electron microscope analysis was performed on all tested samples.
\end{abstract}

Results: Distilled water was found to have a statistically higher bond strength compared to the other irrigation solutions. No statistically significant differences were found
$(P>0.05)$ when bond strength was compared between etch-and-rinse mode, and self-etch mode of adhesive systems. The mean bond strength of floor pulp dentin groups was significantly lower than that of other regions $(P<0.05)$.

Conclusions: The chemical irrigant solutions and dentin regions influenced the adhesive bond strenght.

\section{Keywords}

Chemical irrigants, Regional dentin, Microshear bond strength, Adhesive system, Etch and rinse, Self-etch

\section{Introduction}

As well as a highly adequate apical seal [1], an effective coronal seal [2], is one of the primary goals of a successful endodontic dental treatment. Recently, a large number of adhesive systems have been developed not only to increase the bond strength of composite resins to dentin but also to serve as resistant barriers that prevent coronal micro-leakage, achieve an effective coronal seal, and optimize the sealing of different regional dentins [3].

Adhesion to dentin is influenced by many factors. During root canal treatment, the use of chemical irrigants changes the chemical composition of the dentin

Citation: KAPTAN A, Kılıç V, HÜRMÜZLÜ F, Serper A, KAPTAN A (2019) Effect of Chemical Irrigants on the Bond Strength of a Universal Adhesive System to Dentin-Enamel Junction and Different Dentin Regions. Clin Med Rev Case Rep 6:285. doi.org/10.23937/2378-3656/1410285

Accepted: September 09, 2019: Published: September 11, 2019

Copyright: (c) 2019 KAPTAN A, et al. This is an open-access article distributed under the terms of the Creative Commons Attribution License, which permits unrestricted use, distribution, and reproduction in any medium, provided the original author and source are credited. 
surface [4]. Furthermore, the pulp chamber dentin is exposed to a series of irrigants with different wettability, surface tension, and chelating effects that result in the alteration of its mineral and organic contents as well as its surface energy [4]. Therefore, after irrigation, the dentin tissue may possess irreversibly altered properties that have an impact on its interaction with the material used for coronal sealing [5]. This adhesion mostly involves the cut surface of coronal dentin with a flat surface, smear layer, and smear plugs within the dentin tubules. However, being a complex structure, pulpal floor dentin consists of primary dentin and regular and irregular secondary dentin [6]. Having less mineral content in the presence of regularly oriented parallel bundles of collagen fibers and predominant branches of dentinal tubules, the region of the dentin-enamel junction (DEJ) is rich in organic material $[7,8]$. Moreover, the DEJ has been shown to be distinct from enamel or dentin and considered a fiber-reinforced bond that is moderately mineralized $[7,8]$.

Application of irrigation solutions containing chlorhexidine gluconate and $\mathrm{NaOCl}$ is not sufficient to remove the smear layer completely [9]. To fix this issue, EDTA is used as an adjunct to $\mathrm{NaOCl}$ for removing the smear layer [10]. Tooth survival following root canal treatment depends not only on the apical sealing after efficient chemomechanical debridement of the root canals but is also highly dependent on coronal sealing [11]. Even though the apical seal prevents the leakage process into the periradicular tissue, microorganisms can still enter the canal coronally via the gaps, as well as bacterial products could cause inflammation of the impervious apical part through the lateral surface coronally, resulting in the failure of endodontic therapy [12].

Independent determination of regional adhesions at the coronal and middle level is therefore important. These adhesives create bonds strong enough to endure the contraction forces exerted by polymerized resin composite on dental structures. Many studies $[5,11]$ have focused on the bonding of root canal treatment to adhesive materials in different regions of the dentin, but there are no studies that investigated the bond strength of adhesive systems in the DEJ region. Moreover, no studies have compared the bonding effectiveness between self-etch and etch $\&$ rinse applied to the $D E J$ and different regions of the dentin comprehensively.

Recently, a new family of adhesives known as "universal" or "multi-mode", was introduced in the dental market. To overcome the deficiencies of the previous generations of single-step self-etch adhesives, they were developed to allow for application of the adhesive with phosphoric acid pre-etching in the total etch and selective-etch or no etching approaches in order to achieve a durable bond to enamel and widely accepted with good results from in vitro [13] and in vivo stud- ies [14]. It has been reported that enamel etching with phosphoric acid enhances the bonding performance of these bonding agents [15] and phosphoric acid demineralizes dentin at a greater depth than self-etch adhesive systems can infiltrate. These adhesives also contain copolymers of polyalkenoic acid have been associated with contradictory results regarding their bonding effectiveness when combined with MDP [10-Methacryloyloxydecyl dihydrogen phosphate] [16].

The purpose of this in vitro study was to evaluate the influence of different endodontic irrigation solutions on the microshear bond strength of a universal adhesive system applied in etch \& rinse mode and self- etch mode to the dentin-enamel junction, coronal dentin, pulp dentin chamber, and floor of the pulp. The first null hypothesis is that chemical irrigation solutions do not have a significant effect on the adhesion of the resin composite to the DEJ, coronal dentin, pulp dentin chamber, and floor of the pulp using different apllication procedures of a universal adhesive system. The second null hypothesis holds that the bond strength of different aplication procedures of a universal adhesive system compared to control group is not affected by the use of different irrigation solutions for DEJ and different regions of the dentin.

\section{Materials and Methods}

\section{Specimen preparation}

One hundred and twenty extracted, sound human molars were used. The teeth were cleaned and then stored in an aqueous solution of $0.5 \%$ chloramine-T at $4{ }^{\circ} \mathrm{C}$ for a maximum of one month before use. Using a water-cooled diamond saw, the teeth were mesiodistally sectioned into halves comprising DEJ, coronal dentin, and pulp dentin regions; thus, providing 120 specimens. Then, the floor of the pulp chamber was obtained by sectioning at the mid-point between the floor of the pulp chamber and the root furcation; thus providing 120 specimens (Figure 1). Each specimen was embedded in an acrylic resin block with the dentinenamel junction and dentin surfaces facing up while the other surface of the tooth was totally embedded in the acrylic resin. The specimen surface was then wet-ground with 600-grit silicon carbide paper under a stream of water to create a uniform smear layer and surface roughness.

\section{Experimental groups and application procedures}

The materials and contents used in the study are shown in Table 1. The specimens were randomly assigned to four groups according to the irrigation solutions used:

Group 1: Irrigated with distilled water for $10 \mathrm{~min}$ (control) $(\mathrm{N}=30)$.

Group 2: Irrigated with $5.25 \% \mathrm{NaOCl}$ for $10 \mathrm{~min}$ and 
Load

Crosshead speed : $0.5 \mathrm{~mm} / \mathrm{min}$

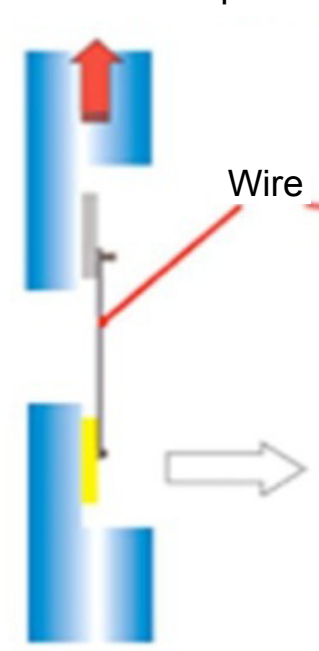

a : DEJ

b : Coronal dentin

c : Pulp dentin chamber

$\mathrm{d}$ : Floor of the pulp

Figure 1: Schematic of how resin specimens were gripped to regions of dentin for testing.

Table 1: The materials and contents used in the study.

\begin{tabular}{|l|l|l|}
\hline Materials & Contents & lot \\
\hline $\begin{array}{l}5.25 \% \text { Sodium Hypochlorite Solution } \\
\text { (Chloraxid-CERKAMED) }\end{array}$ & $\begin{array}{l}\text { Sodium Hypochlorite: } 5.25 \% \\
\text { Water: } 94.75 \%\end{array}$ & - \\
\hline $\begin{array}{l}17 \% \text { EDTA Solution } \\
\text { (MD Cleanser-META BIOMED CO., } \\
\text { LTD) }\end{array}$ & WDTA: $17 \%$ & Water: $83 \%$ \\
\hline $\begin{array}{l}\text { 2\% Chlorhexidin Solution } \\
\text { (EDS Dental, Endo-CHX) }\end{array}$ & $\begin{array}{l}\text { Chlorhexidine Gluconate: } 2 \% \\
\text { Water: } 98 \%\end{array}$ & - \\
\hline $\begin{array}{l}\text { Scotchbond }{ }^{\text {TM }} \text { Etchant Phosphoric } \\
\text { Acid (3M ESPE) }\end{array}$ & $35 \%$ Phosphoric Acid & 621073 \\
\hline $\begin{array}{l}\text { Single Bond Universal Adhesive } \\
\text { (3M ESPE) }\end{array}$ & $\begin{array}{l}\text { MDP Phosphate Monomer, Dimethacrylate resins, HEMA, } \\
\text { Vitrebond TM Copolymer, Filler, Ethanol, Water, Initiators, Silane }\end{array}$ & 593550 \\
\hline $\begin{array}{l}\text { Filtek Bulk Fill Posterior Restorative } \\
\text { (3M ESPE) }\end{array}$ & Bis-GMA, UDMA, Bis-EMA, procrylat resins, YbF3, zirconia, silica & 640699 \\
\hline
\end{tabular}

then rinsed with water for $5 \mathrm{~s}(\mathrm{~N}=30)$.

Group 3: Irrigated with 17\% EDTA for $1 \mathrm{~min}$, flushed with $5.25 \% \mathrm{NaOCl}$ for $10 \mathrm{~min}$, and then rinsed with water for $5 \mathrm{~s}(\mathrm{~N}=30)$.

Group 4: Irrigated with $2 \%$ chlorhexidine gluconate for $10 \mathrm{~min}$ and then rinsed with water for $5 \mathrm{~s}(\mathrm{~N}=30)$.

\section{Bonding procedures}

Experimental groups were divided into two subgroups according to application modes of the adhesive system. The first subgroup was bonded with the Single Bond Universal Adhesive (3M ESPE, Seefeld, Germany) using etch-and-rinse mode, and the second subgroup was bonded using self-etch mode according to the manufacturer's instructions $(n=15)$. After applying the adhesive to the dentin, a vinyl tube (Tygon tubing) 0.75 $\mathrm{mm}$ in diameter and $0.5 \mathrm{~mm}$ high was placed on the dentin-enamel junction and dentin surfaces, then the adhesive was light cured. The Filtek Bulk Fill Posterior (3M ESPE, St. Paul, USA) composite was packed into the cylinder's lumen, a plastic strip was placed over the resin composite, and the material was light-cured for $40 \mathrm{~s}$ using an EliparTM FreeLight 2 LED curing light (3M ESPE, St Paul, MN, USA). The specimens were stored in water at $37{ }^{\circ} \mathrm{C}$ for $24 \mathrm{~h}$. The vinyl tubes were removed with a sharp knife, and then the specimens were checked under a light microscope at X10 magnification to discard any specimens with air bubbles or gaps evident at the interface.

\section{Measurement of microshear bond strength}

A universal testing machine (Lloyd Instruments, Fareham, UK) was used for the microshear bond test. A wire of 0.2-mm diameter was looped around the resin composite and gently held flush against the resin/dentin interface. The wire loop and the center of the load cell were aligned as straight as possible to ensure correct 
Table 2: Regional microshear bond strengths of dentin bonding system after treatment with different irrigation solutions (MPa).

\begin{tabular}{|c|c|c|c|c|}
\hline \multicolumn{5}{|c|}{ Irrıgatıon Solutıons } \\
\hline & Distilled water & $\mathrm{NaOCl}$ & EDTA/NaOCI & Chlorhexidine \\
\hline \multicolumn{5}{|c|}{ Enamel-dentin junction } \\
\hline \multicolumn{5}{|c|}{ Single Bond Universal } \\
\hline Self-etch & $28.6(6.86)^{\mathrm{a}}$ & $19.2(2.77)^{\mathrm{b}}$ & $17.0(2.41)^{c}$ & $19.6(3.85)^{b}$ \\
\hline Etch \& rinse & $28.2(6.80)^{a}$ & $18.9(4.40)^{b}$ & $20.1(4.66)^{b}$ & $21.7(2.64)^{b}$ \\
\hline \multicolumn{5}{|c|}{$F=9.600 \quad P=0.000, P<0.005$} \\
\hline \multicolumn{5}{|c|}{ Coronal dentin } \\
\hline \multicolumn{5}{|c|}{ Single Bond Universal } \\
\hline Self-etch & $26.7(3.37)^{\mathrm{a}}$ & $21.7(2.65)^{b}$ & $20.8(4.59)^{b}$ & $21.0(2.21)^{b}$ \\
\hline Etch \& rinse & $26.0(3.37)^{\mathrm{a}}$ & $18.9(2.21)^{\mathrm{c}}$ & $20.1(3.90)^{\mathrm{b}, \mathrm{c}}$ & $21.2(2.88)^{b}$ \\
\hline \multicolumn{5}{|c|}{$F=5.641 \quad P=0.000, P<0.005$} \\
\hline \multicolumn{5}{|c|}{ Pulp dentin chamber } \\
\hline \multicolumn{5}{|c|}{ Single Bond Universal } \\
\hline Self-etch & $26.3(3.60)^{\mathrm{a}}$ & $18.3(2.85)^{b}$ & $18.1(3.17)^{b}$ & $17.5(2.86)^{\mathrm{b}}$ \\
\hline Etch \& rinse & $25.2(3.06)^{\mathrm{a}}$ & $15.1(4.25)^{c}$ & $14.6(3.88)^{c}$ & $20.7(1.08)^{b}$ \\
\hline \multicolumn{5}{|c|}{$F=18.586 \quad P=0.000, P<0.005$} \\
\hline \multicolumn{5}{|c|}{ Floor of the pulp } \\
\hline \multicolumn{5}{|c|}{ Single Bond Universal } \\
\hline Self-etch & $12.0(1.61)^{\mathrm{a}}$ & $9.8(1.11)^{b}$ & $8.8(1.21)^{b}$ & $8.6(1.17)^{b}$ \\
\hline Etch \& rinse & $11.8(1.06)^{\mathrm{a}}$ & $8.7(1.71)^{b}$ & $8.9(1.62)^{b}$ & $9.8(0.58)^{a, b}$ \\
\hline \multicolumn{5}{|c|}{$F=18.084 \quad P=0.000, P<0.005$} \\
\hline
\end{tabular}

In each row, means with the same lower case superscript letters indicate a nonsignificant difference between groups ( $p>0.05)$.

application of the shear force. A shear force of $0.5 \mathrm{~mm} /$ min was applied until failure occurred. The data in $\mathrm{MPa}$ units were subjected to two-way analysis of variance (ANOVA) and Tukey's test at a significance level of 0.05. Scanning electron microscope analysis was performed on all tested samples in groups.

\section{Results}

Mean, standard deviation, and statistical data obtained by irrigation solutions and adhesive system aplications are shown in Table 2 according to different regions (coronal dentin, pulp dentin chamber, floor of the pulp and dentin-enamel junction). The bond strengths of the distilled water (control) were found to be statistically higher than the irrigation solutions (Chlorhexidine, $\mathrm{NaOCl}$ and EDTA/NaOCl) on DEJ and three different dentin groups (coronal dentin, pulp dentin and floor of pulp dentin) based on the adhesive system aplication modes used $(P<0.05)$. No statistically significant differences were found $(P>0.05)$ in the bond strength between etch-and-rinse mode and self-etch mode of adhesive system in four regions using different irrigation solutions.

When the adhesive systems were applied, the floor of the pulp groups showed significantly lower mean bond strength compared to other regions and experimental groups $(P<0.05)$, but no statistically significant differences in bond strength values were found among
$D E J$, coronal dentin, and pulpal dentin groups $(P>0.05)$. The scanning electron microscope (SEM) analysis images of the fractures are shown in Figure 2.

\section{Discussıon}

Adhesion to the DEJ and different dentin regions was affected by the endodontic chemical irrigants. The results of this study showed that when etch \& rinse and self-etching adhesive systems were applied, chemical irrigants had an adverse effect on the bond strength in DEJ and different regions of the dentin. This result supports our first null hypothesis since no difference was found in the microshear bond strength between the self-etching and etch \& rinse adhesives when bonded to the DEJ and different dentin regions that were irrigated with various endodontic irrigants. The second null hypothesis, that the bond strength of adhesive systems is not affected by the use of different irrigation solutions for DEJ and that different dentin regions is rejected because a drastic reduction was observed in bond strength of adhesive systems compared with the control group.

Previously, $\mathrm{NaOCl}$ treatment had been shown to accelerate the polymerization of bonding resin [17]. It was demonstrated that $\mathrm{NaOCl}$ induces the oxidation of some components in the dentin matrix, forming protein radicals that will compete with the increasing vinyl-free radicals created by the light-activation of resin adhesives, leading to premature chain termination and 

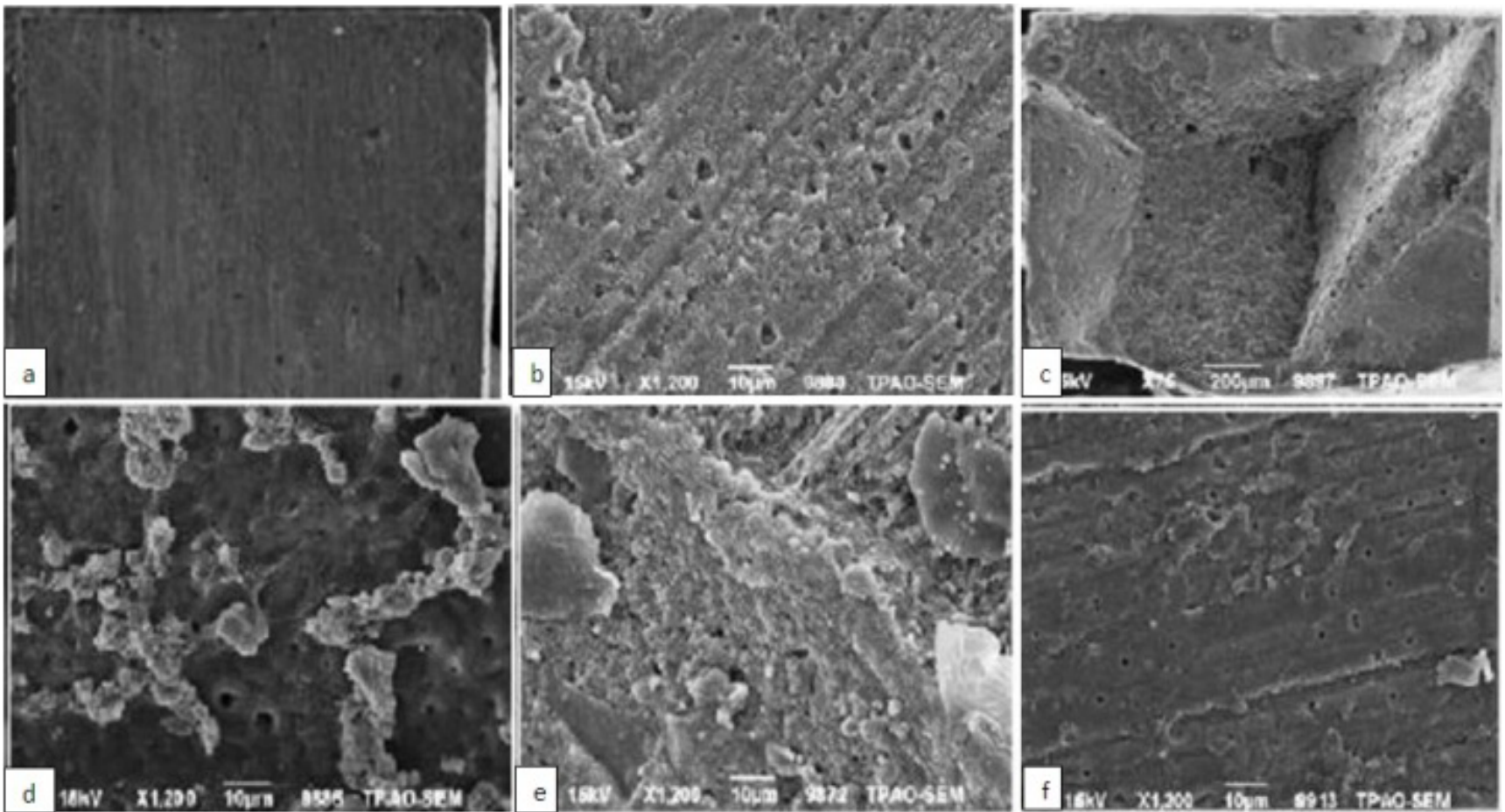

Figure 2: SEM analysis images of the some failures type. a) Adhesive type failure of $\mathrm{NaOCl}$ and self etch group; $\mathrm{B}$ ) Adhesive type failure of EDTA and etch \& rinse group; C) Cohesive type failure of chlorhexidine and self etch mode; D) Mix type failure of EDTA and etch \& rinse group; E) Mix type failure of $\mathrm{NaOCl}$ and self etch group; f) Mix type failure of chlorhexidine and etch $\&$ rinse group.

incomplete polymerization [18]. Due to its small size, the hypochlorite anion can readily infiltrate mineralized collagen and destroy the collagen fibrils, producing a mineral-rich, collagen sparse ghost mineral matrix with reduced flexural strength [19]. Moreover, decreases in calcium and phosphorus levels and changes in mechanical properties of dentin, such as the elastic modulus, flexural strength, and microhardness were reported after irrigation of root canals with $5 \% \mathrm{NaOCl}$, which can also contribute to a reduction in the micromechanical interaction between adhesive resins and $\mathrm{NaOCl}$-treated dentin [20].

The present results showed that successive use of EDTA and $\mathrm{NaOCl}$ led to reduced adhesion of the bonding adhesive systems. EDTA, which demineralizes the inorganic component, and the opposite action of $\mathrm{Na}$ $\mathrm{OCl}$, which dissolves the organic component, probably resulted in demineralization of the dentinal surface and enlargement of the orifices of the dentinal tubules. Repeated application of EDTA and $\mathrm{NaOCl}$ solutions to the dentin, as done in the combined regimen, obviously caused progressive dissolution of both the organic and inorganic components of pretubular and intertubular dentin, which resulted in the loss of the globular surface configuration of the calcospherites and enlargement of the tubular orifices [21]. Significantly lower microshear bond strength was shown when chlorhexidine gluconate was used and it was suggested that remnants of chlorhexidine gluconate could interact with the calcium and phosphate available in the dentin and, therefore, inhibit the bonding ability of the bonding agent [22].
The use of a reliable dentin bonding system allows a root-filled tooth to be restored by replacing only the lost tooth structure, because it should be capable of strengthening the residual tooth structure. For adhesive restoration of a root-filled molar, all regions of the coronal and pulp chamber (i.e. the DEJ, floor, and walls) should be used to gain more surface area for bonding.

The results of this in vitro study showed that the bonding of the two adhesive systems was almost the same in the DEJ region and in different regions of the dentin, with no statistically significant difference. The DEJ had a fracture strength between those of enamel and dentin [23]. While a complex, scalloped pattern between enamel and dentin is a perceptible property of the DEJ, bonding to the DEJ region depends on physical characteristics of dentin and enamel bonding [24].

Differences in bonding to dentin have been shown to be a result of morphological and structural variations in dentin (Figure 2) [25,26]. Similar results were demonstrated in this study. Compared to coronal dentin, the ultrastructure of the dentin at the floor of the pulp chamber seems similar to secondary or reparative dentin and contains irregular, fewer, and narrower tubules, as reported previously $[25,26]$. Tubular irregularities may have occurred because of mineral accumulations, organic components of odontoblast processes, or peritubular deposits. Thus, morphological variations affect the infiltration of adhesive resin monomers into the dentin tubules, leading to weaker bonding in this region [25]. Also, the pulpal floor dentin is rich in organ- 
Enamel-dentin junction failure types

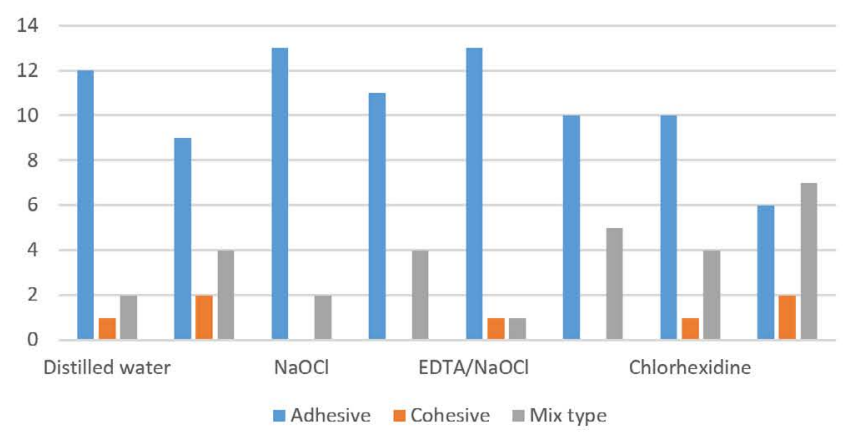

Pulp dentin chamber failure types

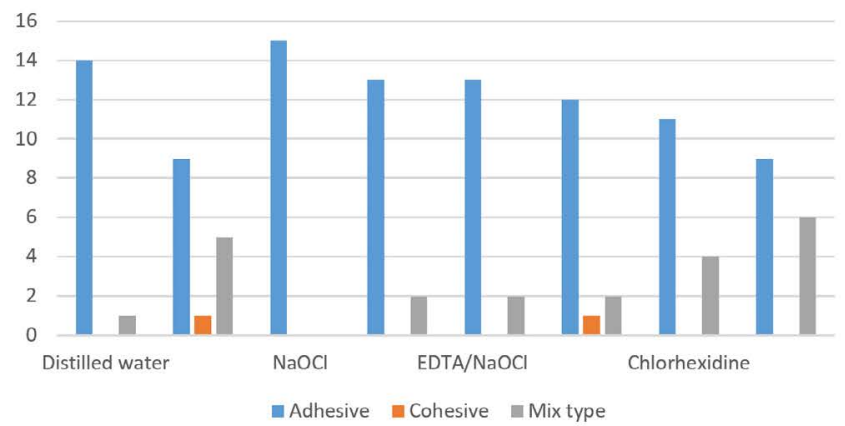

Coronal dentin failure types

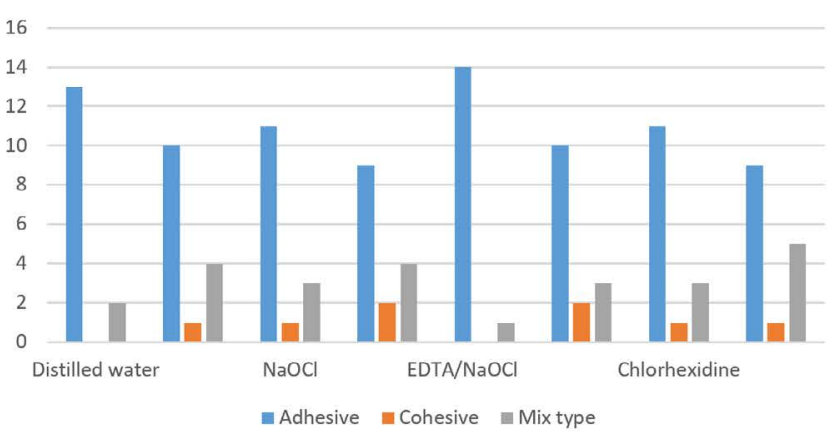

Floor of the pulp failure types

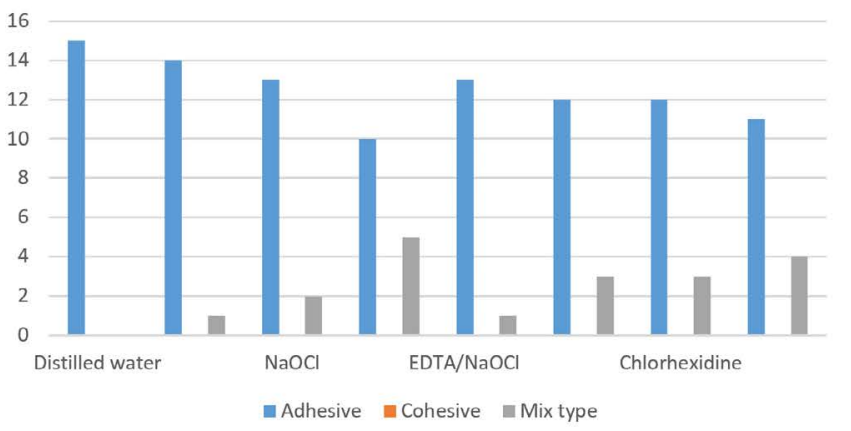

Figure 3: Distrubition of failure types.

ic components and has poor mineral content [27]. The presence of a greater organic content in the pulpal floor may have, in part, resulted in decreased penetration of the monomer [11]. Akagawa, et al. [25] reported that sclerotic and aged dentin showed a thinner hybrid layer, with short resin tags and fewer lateral branches than "normal" dentin.

As an etch-and-rinse system, the Single Bond Universal Adhesive utilizes phosphoric acid, which entirely removes the smear layer and forms a relatively thick zone of demineralized dentin. Increased adhesive failure was shown with decreases in bond strength (Figure 3) [28]. This might indicate less penetration of the resin monomer into the DJE and different regional dentin. The collagen fibrils eroded by the chemical irrigants would easily collapse after phosphoric acid etching, resulting in lower bond strength for the One Step bond in the experimental groups. On the other hand, with the use of the Single Bond Universal Adhesive system's self-etch mode, the acidic resin monomer simultaneously demineralizes and infiltrates the smear layer-covered dentin, resulting in the formation of a thinner hybrid layer. Thus, cohesive failure in the substrates was demonstrated in all experimental groups. This could be attributed to widely demineralized dentin into which the bonding resin could not penetrate completely, contributing to a prone-to-break weak zone [29]. However, adhesion of resin to the DEJ and different regions of dentin has not been fully understood, and further studies are needed to elucidate the mechanism of resin bonding to different regions of endodontically treated teeth.
In the present study, the specimens were prepared for microshear testing which allows for testing of small areas. This test method provides similar results with the micro-tensile test when multiple specimens obtained from the same tooth are examined but does not involve sectioning procedures that may cause premature micro-cracking within the specimens [30].

In this study, no aging process was performed and a single adhesive system and a single restotative material were used. Within the limitations of this study, we found that the chemical irrigants reduced the bond strength of the etch \& rinse and self-etching adhesive systems to the DEJ and different regional dentin. There was no difference in the bond strength between the etch \& rinse and self-etching adhesives in the DEJ and different dentin regions following irrigation with different solutions, whereas the bond strength of the pulpal floor dentin was lower in both adhesive systems.

\section{Conclusion}

Although the irrigation solutions used in this study reduced the bond strength of the etch \& rinse and selfetching mode of adhesive systems to DEJ and different dentin regions, they showed comparable bond strength. Moreover, floor of the pulp region exhibited the lowest bond strength among all regions following application of irrigation solutions.

\section{References}

1. Shipper G, Ørstavik D, Teixeira FB, Trope M (2004) An evaluation of microbial leakage in roots filled with a thermoplastic synthetic polymer-based root canal filling 
material (Resilon). J Endod 30: 342-347.

2. Saunders WP, Saunders EM (1994) Coronal leakage as a cause of failure in root-canal therapy: A review. Endod Dent Traumatol 10: 105-108.

3. Galvan RR Jr, West LA, Liewehr FR, Pashley DH (2002) Coronal microleakage of five materials used to create an intracoronal seal in endodontically treated teeth. J Endod 28: 59-61.

4. Ari H, Erdemir A (2005) Effects of endodontic irrigation solutions on mineral content of root canal dentin using ICP. AES technique. J Endod 31: 187-189.

5. Santos JN, Carrilho MR, De Goes MF, Zaia AA, Gomes $\mathrm{BP}$, et al. (2006) Effect of chemical irrigants on the bond strength of a self-etching adhesive to pulp chamber dentin. $\mathrm{J}$ Endod 32: 1088-1090.

6. Berkovitz BK, Holland GR, Moxham BJ (1992) A Color Atlas and Textbook of Oral Anatomy, Histology and Embryology. ( $2^{\text {nd }}$ edn), Wolfe Publishing, London, UK, 130-145.

7. Lin CP, Douglas WH (1994) Structure-property relations and crack resistance at the bovine dentin- enamel junction. J Dent Res 73: 1072-1078.

8. Mjör IA, Sveen OB, Heyeraas KJ (2001) Pulp-dentin biology in restorative dentistry. Part 1: normal structure and physiology. Quintessence Int 32: 427-446.

9. Scelza MF, Antoniazzi JH, Scelza P (2000) Efficacy of final irrigation--a scanning electron microscopic evaluation. J Endod 26: 355-358.

10. Türkün M, Sevgican F, Aran B (2005) Effect of endodontic irrigants on microleakage of coronal restorations. Am J Dent 18: 353-358.

11. Belli S, Zhang Y, Pereira PN, Ozer F, Pashley DH (2001) Regional bond strengths of adhesive resins to pulp chamber dentin. J Endod 27: 527-532.

12. Wu MK, Wesselink PR (1993) Endodontic leakage studies reconsidered. Part I. Methodology, application and relevance. Int Endod J 26: 37-43.

13. Munoz MA, Luque-Martinez I, Malaquias $P$, Hass $V$, Reis A, et al. (2015) In vitro longevity of bonding properties of Universal Adhesives to dentin. Oper Dent 40: 282-292.

14. Peumans M, De Munck J, Van Landuty KL, Poitevin A, Lam- brechts P, et al. (2010) Eight- year clinical evaluation of a 2-step self-etch adhesive with and without selective enamel etching. Dent Mater 26: 1176-1184.

15. Rosa WL, Piva E, Silva AF (2015) Bond strength of universal adhesives: A systematic review and meta-analysis. J Dent 43: 765-776.

16. Perdigão J, Kose C, Mena-Serrano AP, De Paula EA, Tay LY, et al. (2014) A new universal simplified adhesive: 18-month clinical evaluation. Oper Dent 39: 113-127.

17. Ozturk B, Ozer $\mathrm{F}$ (2004) Effect of $\mathrm{NaOCl}$ on bond strengths of bonding agents to pulp chamber lateral walls. J Endod 30: $362-365$

18. Lai SC, Mak YF, Cheung GS, Osorio R, Toledano M, et al. (2001) Reversal of compromised bonding to oxidized etched dentin. J Dent Res 80: 1919-1924.

19. Gu LS, Huang XQ, Griffin B, Bergeron BR, Pashley DH, et al. (2017) Primum non nocere - The effects of sodium hypochlorite on dentin as used in endodontics. Acta Biomater 61: 144-156.

20. Sim TP, Knowles JC, Ng YL, Shelton J, Gulabivala K (2001) Effect of sodium hypochlorite on mechanical properties of dentine and tooth surface strain. Int Endod J 34: 120-132.

21. Baumgartner JC, Mader CL (1987) A scanning electron microscopic evaluation of four root canal irrigation regimens. J Endod 13: 147-157.

22. Vieira Rde S, da Silva IA Jr (2003) Bond strength to primary tooth dentin following disinfection with a chlorhexidine solution: an in vitro study. Pediatr Dent 25: 49-52.

23. Shimada Y, Iwamoto N, Kawashima M, Burrow MF, Tagami $J(2003)$ Shear bond strength of current adhesive systems to enamel, dentin and dentin-enamel junction region. Oper Dent 28: 585-590.

24. Urabe I, Nakajima S, Sano H, Tagami J (2001) Physical properties of the dentin-enamel junction region. Am J Dent 3: $129-135$.

25. Akagawa $\mathrm{H}$, Nikaido T, Takada T, Burrow MF, Tagami J (2002) Shear bond strengths to coronal and pulp chamber floor dentin. Am J Dent 15: 383-388.

26. Toba S, Veerapravati W, Shimada $Y$, Nikaido T, Tagami $J$ (2003) Micro-shear bond strengths of adhesive resins to coronal dentin versus the floor of the pulp chamber. Am J Dent 16: 51A-56A.

27. Ferrari M, Cagidiaco MC, Davidson CL (1997) Resistance of cementum in Class II and V cavities to penetration by an adhesive system. Dent Mater 13: 157-162.

28. Yoshiyama M, Sano H, Ebisu S, Tagami J, Ciucchi B, et al. (1996) Regional strengths of bonding agents to cervical sclerotic root dentin. J Dent Res 75: 1404-1413.

29. Sano H, Takatsu T, Ciucchi B, Russell CM, Pashley DH (1995) Tensile properties of resin-infiltrated demineralized human dentin. J Dent Res 74: 1093-1102.

30. Ferrari M, Goracci C, Sadek F, Eduardo P, Cardoso C (2002) Microtensile bond strength tests: scanning electron microscopy evaluation of sample integrity before testing. Eur J Oral Sci 110: 385-391. 